\title{
ESTUDIO DE LAS PROPIEDADES FUNCIONALES DE AISLADO PROTELNICO DE TORTA DE COCO
}
L.A. Viena V., ${ }^{*}$
O. M. Mendieta T.*
L. Briceño B. ${ }^{* *}$

\section{RESUMEN}

Se estudió algunas propiedades funcionales del aislado proteínico de torta de coco, obtenido mediante extracción alcalina y precipitación ácida, para conocer el comportamiento de la proteína en un sistema alimentario.

El aislado proteínico presentó buena capacidad de absorber agua $(284 \%)$ y aceite $(160 \%)$ comparado con sus similares; la capacidad de batido fue baja (50\%), pero la espuma resulté ser más estable comparado con la espuma de clara de huevo $(86.32 \%)$. No resulté ser buen estabilizador de emulsiones aceite/agua. La proteína del aislado proteínico de coco presenta buena solubilidad en el rango $\mathrm{pH}$ entre $7 \mathrm{a}$ 10.

Palabras claves Aislado, proteína, coco, propiedades funcionales.

\section{INTRODUCCION}

Actualmente se están produciendo y extrayendo proteínas de fuentes no convencionales para suplementar o sustituir a las proteínas existentes.

Algunas presentan propiedades intrinsecas satisfactorias como valor nutritivo, sabor, color, y textura aceptable; pero poseen propiedades funcionales inadecuadas.

Las propiedades funcionales, no sólo se determinan por su origen; además existen otros factores que influyen en éstas, como las condiciones de procesamiento a que son sometidos, la presencia de otros componentes, etc.

Como las propiedades funcionales son determinantes para predecir el comportamiento de los ingredientes proteicos, se necesita el conocimiento exacto de métodos y condiciones experimentales.

Con el presente trabajo se pretende conocer las propiedades funcionales más importantes del aislado proteico de coco, como absorción de agua y aceite, capacidad

\footnotetext{
* Universidad Nacional San Martín. Facultad de Ingeniería Agroindustrial. Casilla Postal 239 - Tarapoto.

** Universidad Nacional Agraria La Molina. Facultad de Industrias Alimentarías.
} 
de emulsificación y espumación y solubilidad de la proteína para indicar su uso apropiado.

\section{MATERIALES Y METODOS}

Se utilizó aislado proteínico liofilizado, obtenido por extracción alcalina y precipitación ácida, a partir de torta de coco. El aislado presentó color castaño, inodoro e insípido. La composición química del aislado proteínico de torta de coco es como sigue: proteína $91.21 \%$ (b.s), grasa $0.62 \%$, fibra $2.79 \%$, ceniza $1.58 \%$ humedad $4.5 \%$ y pH de dispersión (1:10) 3.9.

\section{ABSORCIÓN DE AGUA}

Método de centrifugación de Janicki y Walczac (1 954) citado por Fleming et al (1 974). El método consiste en preparar una dispersión al 10\% (en base seca) en agua y centrifugando a $2500 \mathrm{rpm}$ por $15 \mathrm{~min}$. Se lee o se mide el volumen de agua suelta, entonces la retención de agua fue computada como agua absorvida ( $\mathrm{ml} \mathrm{de}$ agua absorvida/gr. de proteína).

\section{ABSORCIÓN DE GRASA}

Método descrito por Lin y Humbert (1974). Se adicionó 0.5 gr. de muestra a $3.0 \mathrm{ml}$ de aceite maíz, en un tubo de centrífuga graduada. El contenido fue removido por $1 \mathrm{~min}$. con un alambre delgado para dispersar la muestra en el aceite, después de un período de reposo de $30 \mathrm{~min}$., el tubo se lo centrifugó a 3,200 rpm por $25 \mathrm{~min}$. y el volumen de aceite libre leído. La absorción de aceite se lo expreso en porcentaje como la cantidad de aceite absorbido/100 gr. de muestra a un 14\% de humedad en base seca.

\section{ESTABILIDAD DE LA EMULSIÓN}

Método por Inklaar y Fortuin (1969) con algunas modificaciones. Se pesó aproximadamente $2.5 \mathrm{gr}$. de muestra y se dispersé agitando con $90 \mathrm{ml}$ de agua destilada a $15^{\circ} \mathrm{C}$ en un vaso de $300 \mathrm{ml}$ por $15 \mathrm{~min}$. Se paró la agitación y se adicioné 1.5 gr. de Cloruro de Sodio y se mantuvo agitando por $1 \mathrm{~min}$. Se adicionó desde una bureta, en $5 \mathrm{~min}$. $25 \mathrm{gr}$. de aceite de maíz a $15^{\circ} \mathrm{C}$ para dispersar la proteína agitando con un agitador magnético. Cuando todo el aceite fue adicionado se continuó agitando por $1 \mathrm{~min}$. La emulsión se virtió en 6 tubos de centrífuga de $15 \mathrm{ml}$ de capacidad y se colocó en baño de agua a $85^{\circ} \mathrm{C}$ por $15 \mathrm{~min}$. Se agitó el contenido de los tubos lentamente. Después del calentamiento de $15 \mathrm{~min}$. se centrifugó por 15 min. a $3000 \mathrm{rpm}$. 
La cantidad de aceite separada se midió cuidadosamente con una pipeta graduada de $10 \mathrm{ml}$. se volvió a centrifugar y se midió nuevamente el aceite separado.

\section{ACTIVIDAD Y ESTABILIDAD DE LA ESPUMA}

Método descrito por Lin y Humbert (1974), con algunas modificaciones. Se pesó 2.0 gr. de muestra (14\% de humedad) en un vaso de $25 \mathrm{ml}$ se agregó $66.6 \mathrm{ml}$ de agua destilada. El material sólido se lo dispersé en el agua y llevado a pH neutro. Se batió la suspensión por $6 \mathrm{~min}$. usando un mezclador eléctrico. Antes y después del batido se registré el volumen en una probeta de $200 \mathrm{ml}$ y el porcentaje de volumen incrementado, debido al batido, fue calculado acorde al método de Lawhon y Cater (1971) y Lawhon et al (1972). Después se midió el volumen total de batido, y el volumen de espuma estancada en la probeta también se la registro para el estudio de la estabilidad de la espuma a 0, 5,10, 20, 30, 60, 90 y 120 min. después de batido.

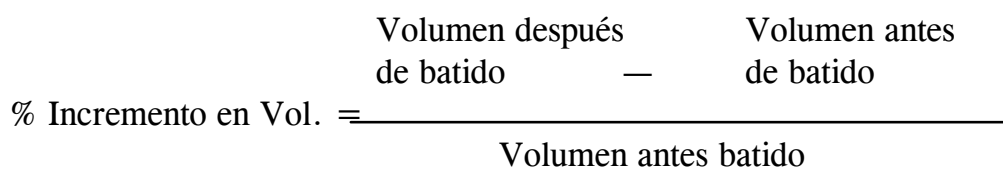

\section{PERFILES DE SOLUBILIDAD DE NITROGENO}

Se los determiné usando el método descrito por Lawhon y Caler (1971) citado por Capulso et al (1981), con algunas modificaciones.

El 0.5 gr de aislado de coco se pesó y dispersé con una espátula en $40 \mathrm{ml}$ de agua destilada. Se ajusté el $\mathrm{pH}$ a valores comprendidos entre 2 y 12 , con $\mathrm{NaOH}$ o HCI 1.ON. Las muestras con una varilla de vidrio por una hora, a temperatura ambiente $\left(28^{\circ} \mathrm{C}\right)$. Se revisé el $\mathrm{pH}$ cada $15 \mathrm{~min}$. y se lo reajusté. Después de una hora, el volumen total fue llevado a $50 \mathrm{ml}$ con agua destilada para llegar a $1 \%(\mathrm{w} / \mathrm{v})$ de concentración de proteína y ajustado el pH. Entonces se centrifugó muestras, se decantó el sobrenadante y se lo pasó a través de un papel filtro; el nitrógeno se lo determiné en una alícuota de $10 \mathrm{ml}$. 


\section{RESULTADOS Y DISCUSION}

\section{ABSORCIÓN DE AGUA}

La capacidad de retener agua del aislado proteínico se muestra en el cuadro 1. Se observa que tiene buena capacidad de absorber agua (284\%) comparado con aislados de palma africana y lupina. Ello se debe a los enlaces de hidrógeno entre las moléculas de agua los grupos polares de las cadenas proteínicas. Por ello se justificaría su empleo en la elaboración de embutidos como aditivo que evite la perdida de agua durante el escaldado y que contribuya a formar y mantener la consistencia y la textura del producto.

\section{ABSORCION DE GRASA}

El cuadro 1 muestra el porcentaje de aceite absorbido (160\%) por el aislado proteínico de coco, considerándolo como bueno, pues al compararlo con los aislados de lupino y palma africana ( $175 \%$ para ambos) no existe diferencia apreciable. Esta buena propiedad posibilitaría su uso en la elaboración de embutidos, lo que permitiría disminuir las perdidas por cocción y ayudaría a mantener la estabilidad del producto cocido.

Además, por su buena capacidad de absorber agua y aceite, el aislado proteínico de coco puede tener usos diversos, como por ejemplo, incorporarlo en mezclas de harinas comestibles.

\section{Cuadro 1}

ABSORCIÓN DE AGUA Y ACEITE DEL AISLADO PROTEÍNICO DE TORTA DE COCO COMPARADO CON PRODUCTOS SIMILARES

\begin{tabular}{lcc}
\hline & Absorción & \multicolumn{2}{c}{ Absorción } \\
& de agua & de aceite \\
& $(\%)$ & $(\%)$ \\
\hline Aislado proteínico coco & 284 & 160 \\
Aislado proteínico Lupino $^{1}$ & 100 & 175 \\
Concentrado proteínico Palma $^{2}$ & 250 & 175 \\
\hline
\end{tabular}




\section{ESTABILIDAD DE LA EMULSIÓN}

Es otra de las propiedades importantes de estos productos. El cuadro 2 presenta el porcentaje de aceite separado del aislado proteínico de coco y de un aislado proteínico de soya (PRIMINE D). Como se podrá observar, el aislado de coco no es buen estabilizador de emulsiones aceite/agua, en los procesos de calentamiento, pues apenas el $21.55 \%$ de aceite es retenido por las proteínas. Tal como señala Inklaar y Fourtuin (1969) el NSI, juega un papel importante en la estabilidad de estos tipos de emulsiones, pero hay que indicar también que el NSI es correlativo con el valor del $\mathrm{pH}$; es decir, el NSJ es alto a valores de $\mathrm{pH}$ alto. Esto es nuevamente confirmado por Capulso, Gonzales y Celestino (1981) que encontraron en un aislado de leche de coco descremada un porcentaje de aceite separado de $90.14 \%$ con un valor de WSP (solubilidad de la proteína en agua) de $14.46 \%$.

\section{Cuadro 2}

\section{ESTABILIDAD DE LA EMULSIÓN CON AISLADOS PROTEÍNICOS DE TORTA DE COCO Y SOYA}

\begin{tabular}{lccc} 
Producto & $\mathrm{pH}$ & NSI & $\begin{array}{c}\% \text { Aceite } \\
\text { separado }\end{array}$ \\
\hline $\begin{array}{l}\text { Aislado prot. coco } \\
\begin{array}{l}\text { Aislado prot. soya } \\
(\text { PROMINE D) }\end{array}\end{array}$ & 3.9 & 6.02 & 78.45 \\
\hline
\end{tabular}

* Inklaar y Fourtuin (1969)

\section{BATIDO Y ESTABILIDAD DE LA ESPUMA}

Los incrementos de volúmenes logrados bajo las condiciones del experimento de esta prueba, fueron para el aislado proteínico de coco de $50 \%$, para la clara de huevo $163 \%$ y para la harina de coco de $1.5 \%$. Se observa claramente que las materias no proteicas contenidas en la harina interfieren en la capacidad de espumación. 
Hay que aclarar que la dispersión de la proteína de coco se efectuó a $\mathrm{pH}$ neutro, pues a pH 3.9, cercano al punto isoléctrico de la proteína no se logró espumación. Aun así, la capacidad de espumación obtenida fue baja (50\%) comparada con la capacidad de espumación de la cara de huevo (163\%). Esto debido a la baja solubilidad de la proteína de coco, lo cual es confirmado por Peltonen Shalaby y Mangino (1986).

El gráfico 1, muestra la estabilidad de la espuma en el período de dos horas. En la curva de estabilidad de espuma de la clara de huevo, se puede apreciar que es muy inestable en los primeros $30 \mathrm{~min}$., mientras que el aislado proteínico de coco es mucho más estable hasta las dos horas. Se observa que la espuma de la clara de huevo disminuye de volumen desde $76 \mathrm{ml}$ a $54 \mathrm{ml}$; es decir en, $28.94 \%$, mientras que el aislado proteínico de coco disminuye de $38 \mathrm{ml}$ a $32.8 \mathrm{ml}$ es decir en $13.65 \%$, concluyendo que la espuma del aislado proteínico de coco es más estable $(86.32 \%)$ que la clara de huevo $(71.06 \%)$.

\section{PERFILES DE SOLUBILIDAD DE NITRÓGENO}

El efecto del pH en la solubilidad de nitrógeno se presenta en el gráfico 2 . El aislado proteínico de coco, posee buena solubilidad en el rango $\mathrm{pH}=8.0$ y por el lado ácido a $\mathrm{pH}=2.0$. El máximo de proteína solubilizada en el lado ácido fue de $72 \%$, mientras que a $\mathrm{pH}=10.0$ fue de $83.09 \%$ descendiendo a medida que se incrementa el $\mathrm{pH}$, indicándonos una posible hidrólisis de la proteína. La baja solubilidad es observada en el rango de $\mathrm{pH}=3.5-6.0$, similares observaciones han sido informados por Samson, Cater y Mattil (1971).

\section{BIBLIOGRAFIA}

CAPSUO, S.A., A.L. GONZALES y V.G. CELESTINO (1981). "Studies Qn the Isolation and Functional Characteristics of Protein from Coconutt Skim Milk". The Philippine J. Sc. 2 (1- 2):25-32.

FEMING, S.E. et al (1974). "Viccosity and Water Absortion Characteristics of Slurries on Sunflower and Soybean Flours Concentrates and Isolates". J. Food Sc. 39: 188-191.

INKLAAR, P.A. y J. FOURTIUN (1969). "Determining the Emulsifying and Emulsion Stabilizing Capacity of Protein meat additives”. Food Tech. 23:103107. 
LAWHON, J.T. et al (1972). "Utilization of Cottonseed whey Protein Concentrates Produced by Ultrafitration”. J. Food. Sc. 39:186-187.

UN, M.J.Y. and E.S. HUMBERT (1974). "Cetain Functional Properties of Sunflower meal Products”. J. Food Sc. 39:368- 370.

PACHECO, E. (1984). "Concentrados proteínicos de palma africana (Elaeis guineensis J.), Proceso de extracción y propiedades funcionales”. Arch. Lat. Nutri. 35(3):509-519.

PELTONEN - SHAABY and M.E. MANGINO (1986). "Comppositional Factors that affect the emulsyifing and foaming proporties of wher protein concentrates". J. Food Sc. 51(1):91-95.

RODRIGUEZ, P. 1981). "Obtención de aislado proteico a partir de Lupino (Lupinus mutábilis)". Tesis para optar título de Ing. Ind. álim. UNA-La Molina.

SAMSON, A.S. J.C,M. CATER, and K. MATTIL (1971). "Preparation and Characterization of Coconut Protein Isolates". Cereal Chemist marzo: 182189. 


\section{Gráfico 1}

PERFILES DE SOLUBILIDAD DE NITROGENO DEL AISLADO PRETEINICO DE COCO

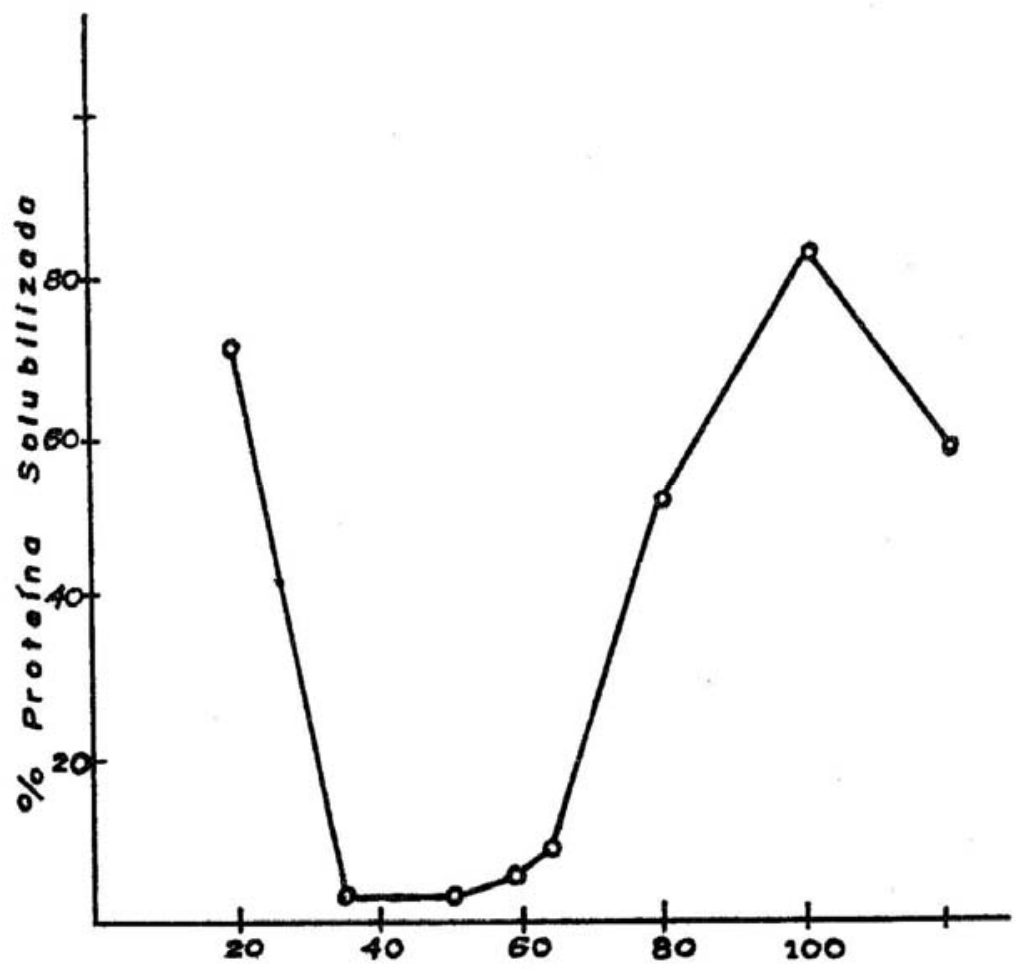




\section{Gráfico 2}

ESTABILIDAD DE LA ESPUMA DE AISLADO PROTEINICO DE COCO, CLARA DE HUEVO Y HARINA DE COPRA

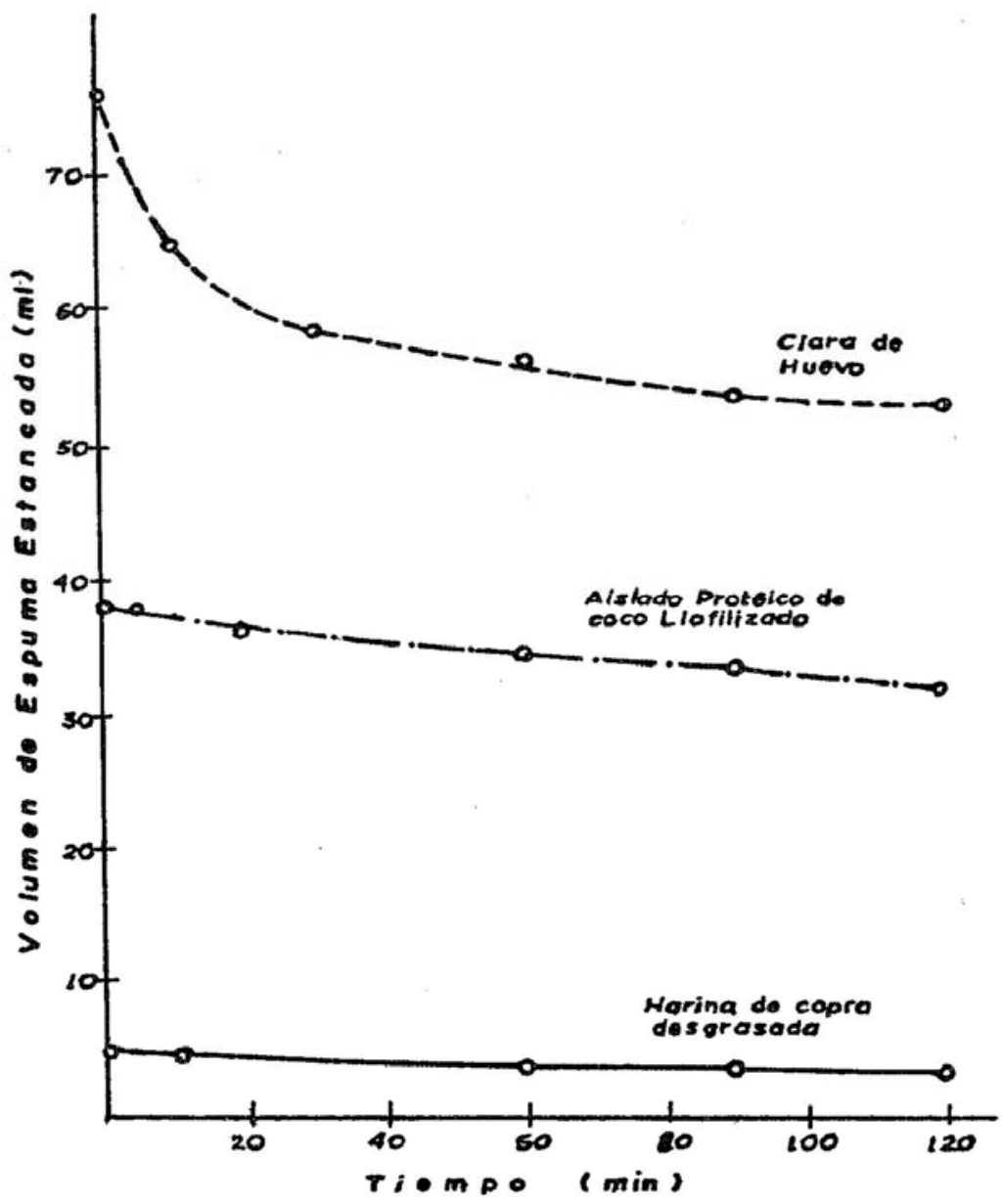

